\title{
RELACְ̃̃ES ENTRE TEORIA E PRÁTICA NA FORMAC̦ÃO DE PROFESSORES: INVESTIGANDO PRÁTICAS SOCIAIS EM DISCIPLINA ACADÊMICA DE UM CURSO NAS CIÊNCIAS BIOLÓGICAS
}

\author{
Gabriel Menezes Viana* \\ Danusa Munford** \\ Márcia Serra Ferreira*** \\ Luciana Moro****
}

RESUMO: Este trabalho apresenta uma pesquisa voltada para o estudo de processos de construção das relações entre teoria e prática na formação de professores. A investigação ocorreu em uma disciplina acadêmica de um curso de Licenciatura em Ciências Biológicas. A disciplina era oferecida em um Instituto de Ciências Biológicas, abordando o ensino de saúde na educação básica a partir do conteúdo específico de Patologia. Investigamos aspectos das práticas sociais em diferentes atividades da disciplina e buscamos caracterizar conhecimentos mobilizados. Empregamos um desenho naturalista, utilizando métodos de pesquisa qualitativa. As análises partem de modelos de formação docente discutidos na literatura. Os resultados indicam que as relações entre teoria e prática variavam de acordo com o tipo de atividade desenvolvida. Apesar de certa predominância do conhecimento biológico, observamos iniciativas da professora que evidenciam preocupação com conhecimentos educacionais, do contexto escolar e do aluno.

Palavras-chave: Teoria e Prática; Formação de Professores de Ciências; Práticas Sociais; Conhecimento do Professor; Prática como Componente Curricular.

\footnotetext{
*Doutorando em Educação pela Universidade Federal de Minas Gerais (UFMG). E-mail: gabrielmenezesviana@gmail.com

* * Doutora em Educação pela Pennsylvania State University e Professora da Universidade Federal de Minas Gerais (UFMG). E-mail: danusa@ufmg.br

** *Doutora em Educação pela Universidade Federal do Rio de Janeiro (UFRJ) e Professora da Universidade Federal do Rio de Janeiro (UFRJ). E-mail: marciaserra.f@gmail.com

****Doutora em Patologia pela Universidade Federal de Minas Gerais (UFMG) e Professora da UFMG.

E-mail: moro@icb.ufmg.br
} 


\section{RELATIONSHIPS BETWEEN THEORY AND PRACTICE IN TEACHER EDUCATION: INVESTIGATING SOCIAL PRACTICES IN AN ACADEMIC DISCIPLINE IN A BIOLOGY TEACHING PROGRAM}

ABSTRACT: In this study, we analyze processes of construction of relationships between theory and practice in teacher education. The investigation took place in a content-specific methods course in a biology-teaching program. The course was offered in a Biological Sciences Institute, addressing health teaching in elementary education. We investigated aspects of social practices in different activities of the discipline and sought to characterize the knowledge addressed. We adopted a qualitative approach with a naturalistic design. The analyses were initially based on models of teacher education discussed in the literature. Results indicate that the relationship between theory and practice varied according to the activity developed. Despite the prevalence of biological knowledge, we identified evidence of the professor's concern with educational and contextual knowledge, as well as with knowledge about students.

Keywords: Theory and Practice; Science Teacher Education; Social Practices; Teachers'knowledge; Methods Courses.

\section{INTRODUÇÃO}

Neste trabalho temos a intenção de contribuir para o conhecimento acerca de como os sentidos das relações entre teoria e prática são construídos nos currículos da formação inicial de professores. Nele investigamos os modos como uma professora formadora organiza e desenvolve atividades em uma disciplina acadêmica de um curso de Licenciatura em Ciências Biológicas. Procuramos perceber quais conhecimentos foram mobilizados no dia a dia da sala de aula e, para tal, consideramos as relações entre os diferentes atores sociais da sala de aula do ensino superior e os artefatos utilizados e produzidos na referida disciplina acadêmica ${ }^{1}$.

A produção na área de Educação que trata sobre a formação de professores vem crescendo significativamente nessas três últimas décadas no Brasil². Entre esses estudos, a formação inicial e as licenciaturas despontam, respectivamente, como a categoria e a subcategoria que apresentam maior volume de trabalhos e pesquisas (ANDRÉ, 2002; BRZEZINSKI, 2006). Tal interesse na formação inicial de professores pode estar relacionado à concomitante expansão da rede pública e privada do ensino fundamental (GATTI; BARRETO, 2009). Gatti e Barreto (2009) nos lembram que a escolarização básica, por volta de fins da década de 1970 e início dos anos 1980, conseguiu deixar de ser privilégio de poucos (membros de famílias 
de classes econômicas mais altas) para abranger grande parte da população brasileira ${ }^{3}$. Observa-se também, nessa época, a criação de comissões e comitês, de congressos, conferências e encontros com o intuito de se pensar a formação de professores ${ }^{4}$ e, em especial, as licenciaturas. Posteriormente, isto é, nos anos 2000, temos a publicação de dispositivos legais que novamente colocam a formação inicial de professores no centro do debate acadêmico sobre o tema ${ }^{5}$.

Desde o seu surgimento, as licenciaturas lidam com o desafio de formar o professor de um conteúdo específico da educação básica, pressupondo-se que esses cursos devem contemplar, além dos conteúdos da ciência de referência específica, aqueles relacionados ao exercício da docência. Pesquisadores como Shulman (1987), Gauthier et al. (1998) e Tardif (2004), entre outros, vêm chamando a atenção para a complexidade de um conjunto de saberes necessários para a docência, o qual envolveria, por exemplo, além do conhecimento de conteúdo, outros conhecimentos como: i) pedagógico de conteúdo, ii) das ciências da educação, iii) do currículo da educação básica, iv) dos alunos, v) dos contextos educacionais e, vi) das finalidades educativas.

Dentre as pesquisas sobre as licenciaturas, aquelas que tomam os cursos de formação de professores em Biologia como objeto de pesquisa ocorrem em um número relativamente menor de trabalhos (7) quando comparadas ao número de pesquisas em outras licenciaturas, como em Matemática (24) e Educação Física (19), realizados no mesmo período (ANDRÉ, 2002; BRZEZINSKI, 2006). No campo da Educação em Ciências, a formação inicial de professores de Ciências e Biologia parece ainda não ter atraído significativa atenção. Afinal, conforme aponta Eduardo Terrazzan (2007, p. 146), especificamente nesse campo, “[...] a tradição brasileira de atuação dos pesquisadores e dos formadores de modo geral fixou-se muito fortemente nas ações de formação continuada de professores".

Com relação às abordagens teórico-metodológicas, a grande maioria das pesquisas sobre formação de professores constitui-se de estudos de caso associados a análises documentais e entrevistas (ANDRÉ, 2002; BRZEZINSKI, 2006). No caso da Educação em Ciências, o quadro não é diferente, uma vez que são escassas as investigações voltadas para uma análise das interações em sala de aula e sobre os discursos produzidos no âmbito da formação de professores (KELLY, 2007). Apesar de algumas 
exceções, essa lacuna na produção acadêmica indica certo descompasso entre as abordagens que vêm sendo adotadas e as visões formativas que predominam, hoje, no campo de pesquisa sobre o tema.

Nesse campo destaca-se como um dos construtos centrais a noção de "saberes docentes" (GAUTHIER et al., 1998), a qual vem sendo apropriada de diversas formas nos estudos, assumindo variados sentidos em função das múltiplas interlocuções que seus autores vêm assumindo (BORGES, 2002). Porém, de modo geral, compartilha-se a visão de que a formação de professores poderia ser entendida como um processo de construção de saberes docentes que ocorre em diferentes espaços educativos. Assim, ganha sentido o posicionamento de autores como Putman e Borko (2000), para os quais as discussões acerca das noções de conhecimento e de aprendizagem que emergem no campo educacional, associadas a contextos da educação básica, deveriam ter implicações significativas para as pesquisas que tomam a formação de professores como objeto de estudo. Torna-se instigante, portanto, ampliar as pesquisas que se voltam para o cotidiano das salas de aula do ensino superior, assim como para as interações discursivas produzidas nos diferentes contextos da formação inicial de professores.

Particularidades da formação de professores em Ciências Biológicas podem contribuir para uma melhor compreensão dos processos de construção dos saberes docentes. Afinal, em currículos ainda marcados pelo modelo formativo que ficou conhecido como " $3+1$ ", os alunos desse curso iniciam seus estudos, preferencialmente, cursando disciplinas acadêmicas voltadas para o ensino das Ciências Biológicas, em estreita articulação com a formação para a pesquisa e, no máximo, com alguma experiência de "docência acadêmica" (SELLES; FERREIRA, 2009). Nesse contexto, aspectos relativos aos tempos e aos espaços específicos da produção dos conhecimentos biológicos "invadem" o imaginário dos futuros professores, criando uma série de conflitos epistemológicos e ressignificando as relações de poder que marcam os processos de formação para a docência. Essas diferenças tornam-se ainda mais pertinentes se considerarmos a questão das relações entre teoria e prática (DINIZ-PEREIRA, 2011), uma vez que existem distintos sentidos sendo produzidos e colocados em disputa, para ambos os termos e para as relações entre eles, nos variados ambientes de pesquisa e de docência escolar. 
Além disso, a formação de professores carrega e ressignifica sentidos anteriores de prática que se referem às vivências que os licenciandos carregam dos longos anos de escolarização que possuem. Tomando como referência o fato de essa experiência distinguir e influenciar de modo significativo a formação de professores de outras formações profissionais, autores como Selles e Ferreira (2009, p. 57-58) destacam três elementos que devem ser enfatizados pelos formadores de professores. São eles:

(i) é preciso problematizar os traços que distinguem os conhecimentos escolares dos conhecimentos científicos e acadêmicos de referência, particularmente aqueles advindos das Ciências Biológicas; (ii) devemos reconhecer o quanto essas diferenças foram constituindo-se em dinâmicas sócio-históricas entrelaçadas, refletindo certas finalidades da escolarização que ora os aproximava ora os afastava entre si [...]; (iii) [devemos] focalizar as tensões e os mecanismos próprios da escola, reconhecendo-a como um lugar de produção de conhecimentos e aos professores como elaboradores desses [...].

Isso significa que não podemos aceitar as longas experiências pré-profissionais dos licenciandos como suficientes para o exercício da docência. Tampouco podemos aceitar somente as experiências formativas adquiridas em uma formação de caráter bacharelesco, voltada para a atuação como biólogo, como suficientes na formação inicial de professores. Entendemos que caminhar nessas duas direções nos faria resgatar concepções do senso comum de que para ser professor não seria necessária uma formação acadêmica institucionalizada e supervisionada, uma vez que bastaria ter talento, bom senso, saber o conteúdo, ter cultura, seguir a intuição (GAUTHIER et al., 1998).

Diferentemente, é justamente por entendermos que a docência é uma "profissão aprendida" (SELLES; FERREIRA, 2009, p. 55) na formação inicial, muito embora aí não se esgote, que optamos por investigar, neste artigo, os sentidos das relações entre teoria e prática construídos cotidianamente em uma disciplina de um curso de Licenciatura em Ciências Biológicas. Como a nossa intenção é compreender aspectos acerca daquilo que ocorre nas salas de aula de uma disciplina acadêmica, assumimos uma perspectiva teórico-metodológica que se aproxima da abordagem da etnografia em educação (GREEN; DIXON; ZAHARLICK, 2005). Nessa perspectiva, entendemos que a sala de aula "[...] funciona como uma cultura na qual os membros constroem formas padronizadas de se envolverem 
nas interações uns com os outros, com objetos e em práticas culturais, ao longo do tempo [...]" (CASTANHEIRA, 2004, p. 45). Assim, com vistas a investigar essa cultura, nos voltamos para as práticas sociais que ocorrem naquele espaço, entendendo-as como um conjunto de condutas sociais legitimadas em um dado espaço social. Segundo Angel Pino (2005, p. 107), as práticas sociais são "[...] as várias formas - socialmente instituídas ou consagradas pela tradição cultural dos povos - de pensar, de falar e de agir das pessoas que integram uma determinada formação social”. Nesse sentido, o que as distingue de outras formas de conduta social são dois aspectos: $\left(\mathbf{1}^{\mathbf{0}}\right)$ "[...] terem uma certa configuração (o que as torna identificáveis) que se perpetua num certo tempo e num certo espaço"; $\left(\mathbf{2}^{\circ}\right)$ “[...] veicularem uma significação partilhada pelos integrantes de um mesmo grupo cultural [...]" (PINO, 2005, p. 107). Nesse trabalho, adotamos algumas ferramentas da etnografia em educação com vistas a compreender facetas dos currículos da formação inicial de professores a partir do estudo das práticas sociais em salas de aula da licenciatura.

\section{SENTIDOS EM DISPUTA NOS MODELOS DE FORMAC̣ÃO INICIAL DE PROFESSORES}

Pesquisadores têm dedicado significativa atenção aos estudos e discussões a respeito dos modelos e/ou concepções que vêm historicamente informando a formação de professores no Brasil. Para Santos (2007, p. 237), por exemplo, "[...] certos modelos influenciam a formação docente, a partir de fundamentos de natureza epistemológica e/ou política e de tendências educacionais que predominam em determinados períodos". Andrade (2006), por sua vez, destaca que esses modelos e/ou concepções nos possibilitam refletir acerca dos rumos das políticas mais recentes para a formação de professores no país, sobretudo a partir da Lei n. 9.394/96. Nesse estudo, em concordância com esses autores, revisitamos os modelos e/ou concepções de formação docente compreendendo-os como indícios que nos permitem investigar a produção de políticas de currículo em seus diversos contextos, o que inclui o "contexto da prática" (BALL; BOWE, 1992). Entendemo-os, portanto, como produções discursivas que nos possibilitam aproximações com os acontecimentos das salas de aula interpretando os conhecimentos 
construídos nesses espaços. Isso significa que as racionalidades técnica, prática e crítica não constituem modelos isolados e fixados em tempos históricos específicos; diferentemente, são produtores de sentidos que continuam disputando a hegemonia da formação de professores, ainda que hibridizados entre eles e com outros discursos do presente.

A racionalidade técnica, de acordo com Donald Schön (2000, p. 15) é "[...] uma epistemologia da prática derivada da filosofia positivista, construída nas próprias fundações da universidade moderna, dedicada à pesquisa [...]”. Para esse autor, a "[...] racionalidade técnica diz que profissionais são aqueles que solucionam problemas instrumentais, selecionando os meios técnicos mais apropriados para propósitos específicos [...]" (SCHÖN, 2000, p. 15). Assim, tornando-se hegemônico e produzindo sentidos que dissociam teoria e prática (ANDRADE et al., 2004; SANTOS, 2007), o modelo da racionalidade técnica trouxe significativas implicações para os diferentes cursos de formação inicial de professores, uma vez que nele:

[...] o professor é visto como um técnico, um especialista que aplica com rigor, na sua prática cotidiana, as regras que derivam do conhecimento científico e do conhecimento pedagógico. Portanto, para formar esse profissional, é necessário um conjunto de disciplinas científicas e um outro de disciplinas pedagógicas, que vão fornecer as bases para sua ação. No estágio supervisionado, o futuro professor aplica tais conhecimentos e habilidades científicas e pedagógicas às situações práticas de aula [...] (DINIZ-PEREIRA, 1999, p. 111-112).

Santos (2007, p. 238), ao tecer considerações sobre as implicações do modelo da racionalidade técnica para os currículos profissionais, afirma que esses “[...] são estruturados de tal forma que os conhecimentos teóricos e as técnicas das ciências básicas e aplicadas antecedem as atividades centradas na habilidade de usar teorias e técnicas para solucionar problemas práticos [...]". Para Andrade et al. (2004, p. 11), esse modelo produz sentidos para as relações entre teoria e prática "[...] que supervalorizam e/ou sacralizam os conhecimentos científicos em detrimento da técnica - aqui entendida como ciência aplicada - que, por sua vez, subordina a prática compreendida como aplicação dessa técnica [...]". Nesse movimento, hierarquiza os conhecimentos no currículo, colocando as habilidades ligadas à prática em posições inferiores aos conhecimentos teóricos (SANTOS, 2007, p. 238).

De acordo com Andrade et al. (2004, p. 11) e Santos (2007), portanto, o modelo da racionalidade técnica produziu limites ao constituir sentidos 
que veiculam uma visão limitada de prática. Tais limites são exemplificados por Santos (2007, p. 238) quando destaca duas questões que não são consideradas nesse modelo, a saber: "[...] que uma prática efetiva precisa levar em conta certos fenômenos como complexidade, incerteza, instabilidade, singularidade e conflito de valores [...]"; e "[...] a de envolver uma série de ações que as pessoas não sabem descrever com precisão [...]”. Santos (2007, p. 238) critica, também, o fato de esse modelo manter uma "[...] centralização na questão de solução de problemas [...]”, uma vez que "[...] na prática, os problemas não se apresentam já definidos ou dados ao profissional [...]”.

Além desses autores, existe uma vasta literatura na área que se mostrou (e ainda se mostra) substancialmente crítica ao modelo da racionalidade técnica (ver, por exemplo, SCHÖN, 1983, 1997; ZEICHNER, 1999; ZEICHNER; LISTON, 1996; NÓVOA, 1997; GAUTHIER et al., 1998). Tais considerações certamente repercutiram na formação de professores em Ciências no nosso país, uma vez que pesquisadores como Delizoicov, Angotti e Pernambuco (2003), Ferreira, Vilela e Selles (2003) e Maldaner, Zanon e Auth (2006), entre outros, já há muito se colocam atentos a essas críticas.

Outro modelo que, desde a década de 1980, disputa os sentidos que se pretendem hegemônicos na formação de professores com a racionalidade técnica é o modelo da racionalidade prática. Nesse último, um aspecto que se destaca como significativo é um tratamento da prática docente diferenciado do primeiro, adotando-se, portanto, outra epistemologia da prática ${ }^{6}$. Afinal, de acordo com Andrade et al. (2004), o modelo da racionalidade prática emerge em meio a discussões que reconhecem a complexidade da escola e pretendem produzir soluções para problemas da prática que não estão a priori colocados. Nesse contexto, para autores como Schön (2000) o mais importante na atividade profissional docente é a estruturação desses problemas, uma vez que, como já afirmado, eles não se apresentam ao profissional já previamente definidos. Tal perspectiva claramente se distancia do modelo da racionalidade técnica ao produzir novos sentidos para a relação entre teoria e prática, assumindo a complexidade e a heterogeneidade do contexto escolar como importantes aspectos formativos (ANDRADE et al., 2004).

O professor é percebido, então, como alguém que reflete sobre a sua própria prática profissional, produzindo conhecimentos sobre ela. Destacamos, mais uma vez, as ideias de Schön (1997) quando trata dessa questão. Para ele, nessa circunstância, o professor passa a ser entendido como 
um profissional prático que desenvolve conhecimentos-na-ação, uma vez que reflete na e sobre a sua prática. No modelo da racionalidade prática, os conhecimentos pertinentes à docência são percebidos, portanto, como um conjunto de saberes complexos que não se resumem a um domínio de técnicas aplicáveis a qualquer contexto. Tal perspectiva tem informado uma série de mudanças em uma formação inicial de professores historicamente marcada pela dissociação entre teoria e prática, ainda que os diversos sentidos dessas relações estejam constantemente em disputa.

Há, ainda, um terceiro modelo de formação docente, fundamentado em uma racionalidade crítica que também disputa com a racionalidade técnica e com a racionalidade prática os sentidos que se pretendem hegemônicos na formação de professores. Nele, o professor é visto como alguém que, ao levantar problemas, o faz com uma visão política explícita sobre o assunto (DINIZ-PEREIRA, 2007), recolocando as relações entre teoria e prática em outra perspectiva na formação inicial de professores. Afinal, para autores como Zeichner (2008), a agenda que deve presidir essa formação é a da justiça social, enfraquecendo a hegemonia de modelos e/ou de perspectivas que veiculam sentidos associados à cultura do desempenho e à lógica do mercado.

Tal posicionamento adiciona o adjetivo social aos sentidos de teoria e de prática, ressignificando-os em direção a perspectivas que pensam a escola como uma instituição social. Esses sentidos, de acordo com Andrade (2006, p. 53), no caso da formação de professores, servem menos para a compreensão dos processos de ensino e aprendizagem e mais para a formação de profissionais dotados de "[...] uma racionalidade crítica, questionadora e, em última análise, potencialmente transformadora da realidade". Para esse autor, no entanto, embora os sentidos de teoria e de prática tenham ambos deslizado do pedagógico para o social, [...]" a concepção de professor como intelectual crítico parece aprisionada na teia das racionalidades contra as quais dirige sua interpelação e suas objeções [...]” (ANDRADE, 2006, p. 54).

Reconhecendo que todos esses modelos e/ou concepções estão em disputa na formação inicial de professores, ressignificando os sentidos de teoria e de prática com os quais temos operado historicamente, tomamos a sala de aula das disciplinas acadêmicas como espaço de significação desses embates e de fixações, ainda que provisórias, de tradições e, simultaneamente, de subversões. Sob a perspectiva da etnografia em educação, assumimos 
que o cotidiano de uma sala de aula - o que inclui o ensino superior - não constitui o reflexo ou a reprodução de tradições discursivamente fixadas em cada um dos modelos de formação aqui explicitados. Em perspectiva diversa, em diálogo com Bloome et al. (2008), argumentamos que estudar as relações entre teoria e prática nesses espaços sob a óptica dos referidos modelos implica em buscar como esses contextos estão discursivamente entrelaçados.

Especificamente, entendemos que essa discussão nos fornece diferentes elementos para interpretar os sentidos de prática que circulam nesses modelos de formação docente em articulação com os sentidos de teoria. Nesse contexto, várias questões podem ser formuladas: a quais sentidos de teoria e de prática estamos nos referindo quando falamos sobre a formação inicial de professores? Que sentidos vêm sendo fixados e quais vêm sendo interditados nesse processo? Como eles significam relações de poder mais amplas que permeiam a formação de professores? Neste estudo, ainda que não tenhamos a pretensão de esgotar o debate acerca dessas questões, optamos por abordá-las por meio da análise de um contexto específico de pesquisa: a disciplina acadêmica Laboratório de Ensino de Patologia, que compõe a Prática como Componente Curricular (PCC) de um curso de Licenciatura em Ciências Biológicas de uma instituição federal de ensino superior da região sudeste do país. Como veremos posteriormente, a PCC tem sido legitimada, pela legislação educacional da década de 2000 (BRASIL, 2001a, b, 2002a, b), como um espaço-tempo privilegiado para a construção de relações entre teoria e prática nos currículos da formação inicial de professores.

\section{ASPECTOS METODOLÓGICOS}

Como dissemos anteriormente, neste estudo investigamos os sentidos das relações entre teoria e prática em um contexto específico de pesquisa: a disciplina acadêmica Laboratório de Ensino de Patologia. Ela é parte de um espaço-tempo curricular que tem sido visto como uma novidade na formação inicial de professores (TERRERI, 2008), ainda que em diálogo com as tradições curriculares historicamente produzidas e tornadas hegemônicas nessa formação. Isso significa, portanto, que não compreendemos o novo 
como o resultado de um completo abandono das tradições do passado; diferentemente, percebemos as inovações articuladas com os conteúdos e práticas já existentes, em um processo que inventa tradição ao agregar o tradicional/antigo com o moderno/renovado (FERREIRA, 2005, 2007).

No curso investigado, a referida disciplina acadêmica é obrigatória, ocupa 30 horas da $\mathrm{PCC}^{7}$ e é ministrada por uma docente do Instituto de Ciências Biológicas da instituição. Sua ementa encontra-se voltada para o uso de “[...] estratégias metodológicas para o desenvolvimento de práticas pedagógicas relacionadas às Ciências da Saúde relacionadas com processos patológicos gerais, como inflamações, alterações circulatórias e tumores [...]" (PROJETO POLÍTICO PEDAGÓGICO DO CURSO DE LICENCIATURA EM CIÊNCIAS BIOLÓGICAS, 2010). O cronograma organizado pela professora, em 2011, é apresentado no Quadro 1. A docente, denominada pelo pseudônimo Maria, possui formação acadêmica, em nível de doutorado, na área da saúde, e sua maior experiência no ensino superior era em disciplinas acadêmicas dessa área em cursos de Bacharelado, como Ciências Biológicas, Veterinária, Medicina etc. Recentemente, essa professora passou a lecionar a disciplina acadêmica Laboratório de Ensino de Patologia para a Licenciatura em Ciências Biológicas e, paralelamente, optou por desenvolver atividades de pesquisa na área da Educação por meio de um pós-doutorado.

Nesse estudo, empregamos um desenho naturalista, investigando uma sala de aula do ensino superior a partir de métodos de pesquisa qualitativa (LINCOLN; GUBBA, 1985). Buscamos entender os significados que os participantes atribuem aos fenômenos sociais que acontecem naquele contexto social, de modo a "[...] esmiuçar a forma como as pessoas constroem o mundo a sua volta, o que estão fazendo ou o que está lhes acontecendo em termos que tenham sentido e que ofereçam uma visão rica [...]" (GIBBS, 2009, p. 8).

As aulas foram realizadas semanalmente, com duração de 1 hora e 40 minutos. Dois dias após a aula ocorriam reuniões com a professora formadora, quando ela fazia relatos dos acontecimentos das aulas e suas reflexões sobre o ocorrido. Obtivemos um total de 10 horas de observação e cerca de 20 horas de reuniões com a professora. Todas essas atividades ocorreram ao longo de um semestre letivo. 


\section{Quadro 1}

Cronograma da disciplina analisada.

\begin{tabular}{|c|c|c|c|c|}
\hline Aula & Data & Estrutura & $\begin{array}{c}\text { Principais } \\
\text { Conhecimentos } \\
\text { Mobilizados }\end{array}$ & Questões que emergem \\
\hline 1 & 15/mar. & Aula expositiva & Biológico. & \\
\hline 2 & 22/mar. & $\begin{array}{l}\text { Grupo de } \\
\text { Discussão }\end{array}$ & Do aluno. Da escola. & $\begin{array}{l}\text { Condição e Trabalho } \\
\text { Docente. }\end{array}$ \\
\hline 3 & 29/mar. & $\begin{array}{l}\text { Apresentação de } \\
\text { licenciando }\end{array}$ & $\begin{array}{l}\text { Biológico. Técnicas } \\
\text { Educacionais. }\end{array}$ & 0 lúdico. \\
\hline 4 & 05/abr. & Aula expositiva & Biológico. & \\
\hline 5 & 12/abr. & $\begin{array}{l}\text { Apresentação de } \\
\text { licenciando }\end{array}$ & Biológico. Do aluno. & Éticas e sociais. \\
\hline 6 & 19/abr. & Aula expositiva & Biológico. & \\
\hline 7 & 26/abr. & $\begin{array}{l}\text { Apresentação de } \\
\text { licenciando }\end{array}$ & $\begin{array}{l}\text { Biológico. Técnicas } \\
\text { Educacionais. }\end{array}$ & O lúdico. \\
\hline 8 & 03/maio & $\begin{array}{l}\text { Apresentação de } \\
\text { licenciando }\end{array}$ & Biológico. Do aluno. & $\begin{array}{c}\text { Professor de Biologia e } 0 \\
\text { Profissional da Saúde. }\end{array}$ \\
\hline 9 & 10/maio & $\begin{array}{l}\text { Apresentação de } \\
\text { licenciando }\end{array}$ & Biológico. Do aluno. & $\begin{array}{c}\text { Papel do Professor de } \\
\text { Biologia. }\end{array}$ \\
\hline 10 & 17/maio & $\begin{array}{l}\text { Apresentação de } \\
\text { licenciando }\end{array}$ & $\begin{array}{l}\text { Biológico. Técnicas } \\
\text { Educacionais. }\end{array}$ & O lúdico. \\
\hline 11 & 24/maio & Aula expositiva & Biológico. & \\
\hline 12 & $31 /$ maio & $\begin{array}{l}\text { Apresentação de } \\
\text { licenciando }\end{array}$ & Biológico. Do aluno. & Dom para o ensino. \\
\hline 13 & 07/jun. & Leitura & $\begin{array}{c}\text { Técnicas } \\
\text { Educacionais. }\end{array}$ & $\begin{array}{l}\text { Escola. Currículo escolar. } \\
\text { Avaliação. Pesquisa em } \\
\text { Ensino de [...]. Ética. }\end{array}$ \\
\hline 14 & 16/jun. & $\begin{array}{l}\text { Grupo de } \\
\text { Discussão }\end{array}$ & Do aluno. Da escola. & \\
\hline 15 & 30/jun. & $\begin{array}{l}\text { Apresentação de } \\
\text { licenciando }\end{array}$ & Biológico. Do aluno. & Éticas e sociais. \\
\hline
\end{tabular}

Nossas análises foram desenvolvidas a partir de registros das reuniões com a professora Maria, de artefatos produzidos para e na disciplina acadêmica e de notas de campo produzidas a partir de observação participante em sala de aula (SPRADLEY, 1980). Nas reuniões, tivemos a intenção de compreender como a professora percebia a sala de aula, assim como os princípios que organizavam suas ações. Os relatos nos forneceram, portanto, 
uma descrição das práticas nas quais os participantes estavam engajados na perspectiva da professora. Os artefatos analisados foram produzidos pela professora (anotações sobre a turma, planejamentos de aulas, relatórios e apresentações em Power Point e Data Show) e pelos alunos (apresentações em Power Point e Data Show e materiais produzidos para suas apresentações). Além disso, foram considerados artefatos que não necessariamente foram produzidos na disciplina, mas que já existiam na instituição e na sala de aula (por exemplo: carteiras, cadeiras, mesas, lousa, projetores, materiais didáticos, infraestrutura) (SPRADLEY, 1980). Procuramos, nas diversas fontes, perceber quais eram e como estavam sendo construídas as relações entre teoria e prática naquele contexto específico.

Inspirados na análise desenvolvida por Kelly e Crawford (1997) ${ }^{8}$, identificamos e organizamos as principais fontes de sentidos das relações entre teoria e prática na disciplina estudada conforme apresentado na Figura 1. Assim foi possível caracterizar as atividades desenvolvidas em relação a uma série de aspectos e categorizar as atividades em diferentes grupos.

Uma vez que as atividades foram caracterizadas a partir desses aspectos das práticas sociais que nela se desenvolviam, passamos a analisar os conhecimentos que circulavam e eram mobilizados pelos participantes em cada tipo de atividade. A categorização teve inspiração no trabalho de autores do campo da formação de professores, em particular autores

\section{Figura 1}

\section{Taxonomia de análise das fontes de visões disponíveis na disciplina estudada.}

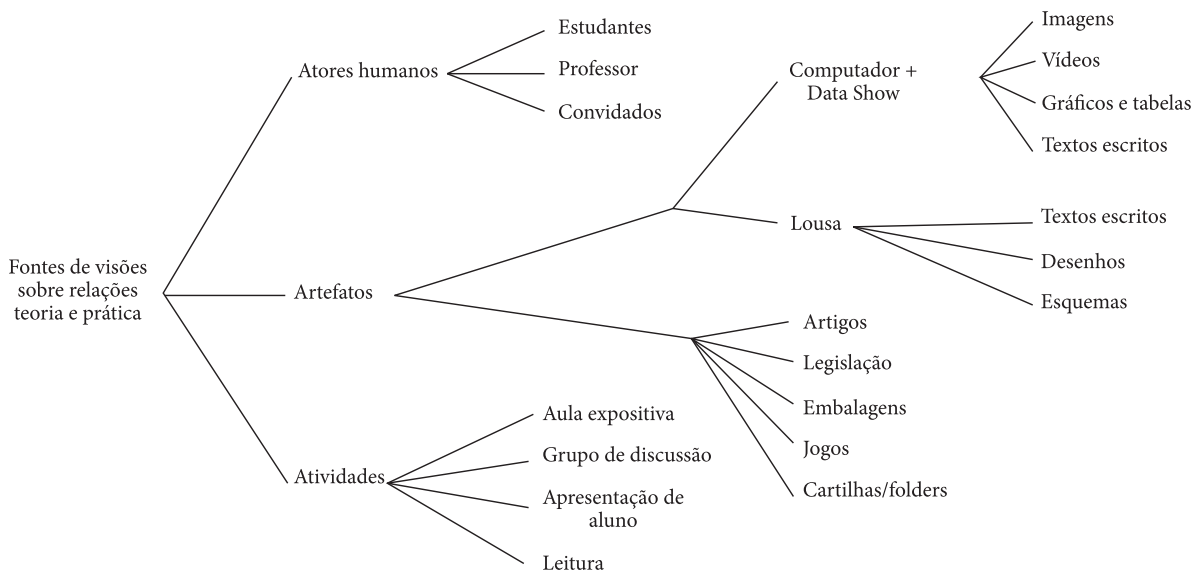


que trabalham dentro do paradigma do conhecimento do professor (MARCELO, 1998). Destacam-se os trabalhos de Lee Shulman (1986) sobre o conhecimento pedagógico do conteúdo (e releituras contemporâneas) e o trabalho de Gauthier et al. (1998). Além disso, agregamos às categorizações do conhecimento do professor apresentadas por esses autores uma discussão sobre modelos de formação que possibilitou melhor qualificar esses conhecimentos. Utilizamos esses referenciais para orientar nosso olhar na análise de dados, mas permanecemos sensíveis a elementos presentes nos dados, em particular àqueles relacionados ao contexto e àqueles que pareciam fazer sentido para os participantes (licenciandos e/ou professora formadora). Nesse diálogo foram geradas as descrições apresentadas na próxima seção.

\section{UM OLHAR SOBRE PRÁTICAS SOCIAIS NA SALA DE AULA DA LICENCIATURA}

As ações desenvolvidas na disciplina acadêmica Laboratório de Ensino de Patologia foram agrupadas em quatro categorias, sendo denominadas atividade 1 , atividade 2 (esta subdividida em $2 \mathrm{~A}$ e $2 \mathrm{~B}$ ), atividade 3 e atividade 4 . O Quadro 2 sumariza diversas características dessas atividades.

O Quadro 3, a seguir, apresenta uma descrição sobre as ações no contexto das práticas sociais desenvolvidas nas diferentes atividades realizadas na disciplina.

A categoria atividade 1 agrupa um conjunto de aulas ministradas pela professora formadora, em geral, de forma expositiva e com o uso de Power Point e Data Show. Em sua perspectiva, o objetivo desse tipo de atividade era suprir uma deficiência que alguns alunos poderiam ter em relação aos conhecimentos biológicos, uma vez que não tiveram contato com tais conteúdos de Patologia em outras disciplinas acadêmicas do curso. Nessa direção, Maria afirma que: "[...] há alunos que não fižeram [as disciplinas que abordam aspectos conceituais da Patologia] e, assim, não tiveram contato com esses conteúdos". Suas aulas teriam, portanto, o propósito de:

[...] passar conceitos [do campo das Ciências Biológicas/Patologia] para que eles pudessem aplicá-los em suas exposições [apresentação de aulas para educação básica que os licenciandos realizavam na disciplina]. Alguns desses termos utilizados mais no significado técnico, tumor, neoplasia [...] o aluno tem de saber. Se ele não tem consciência desses termos isso pode dificultar a exposição dele ${ }^{10}$. 


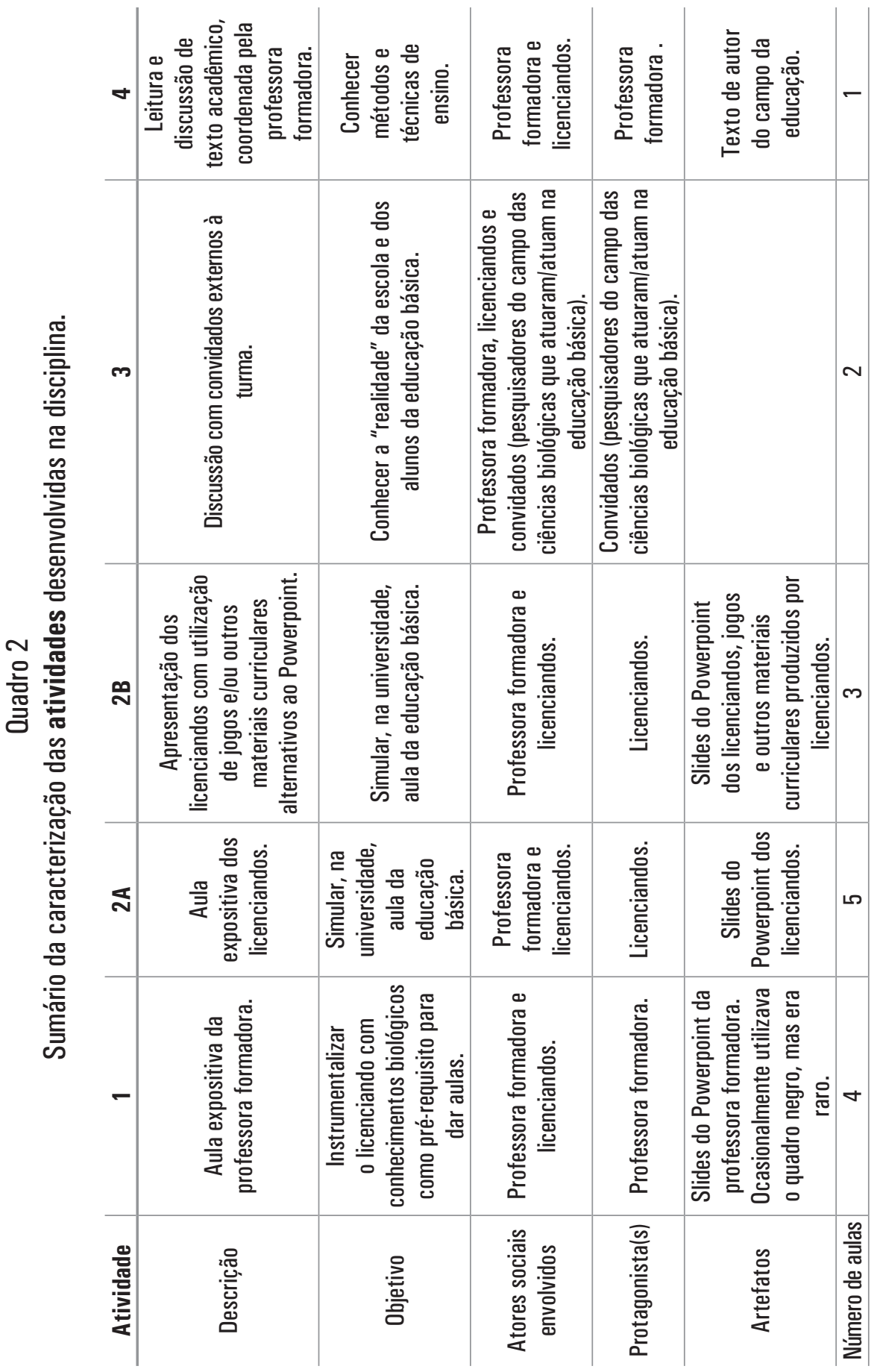




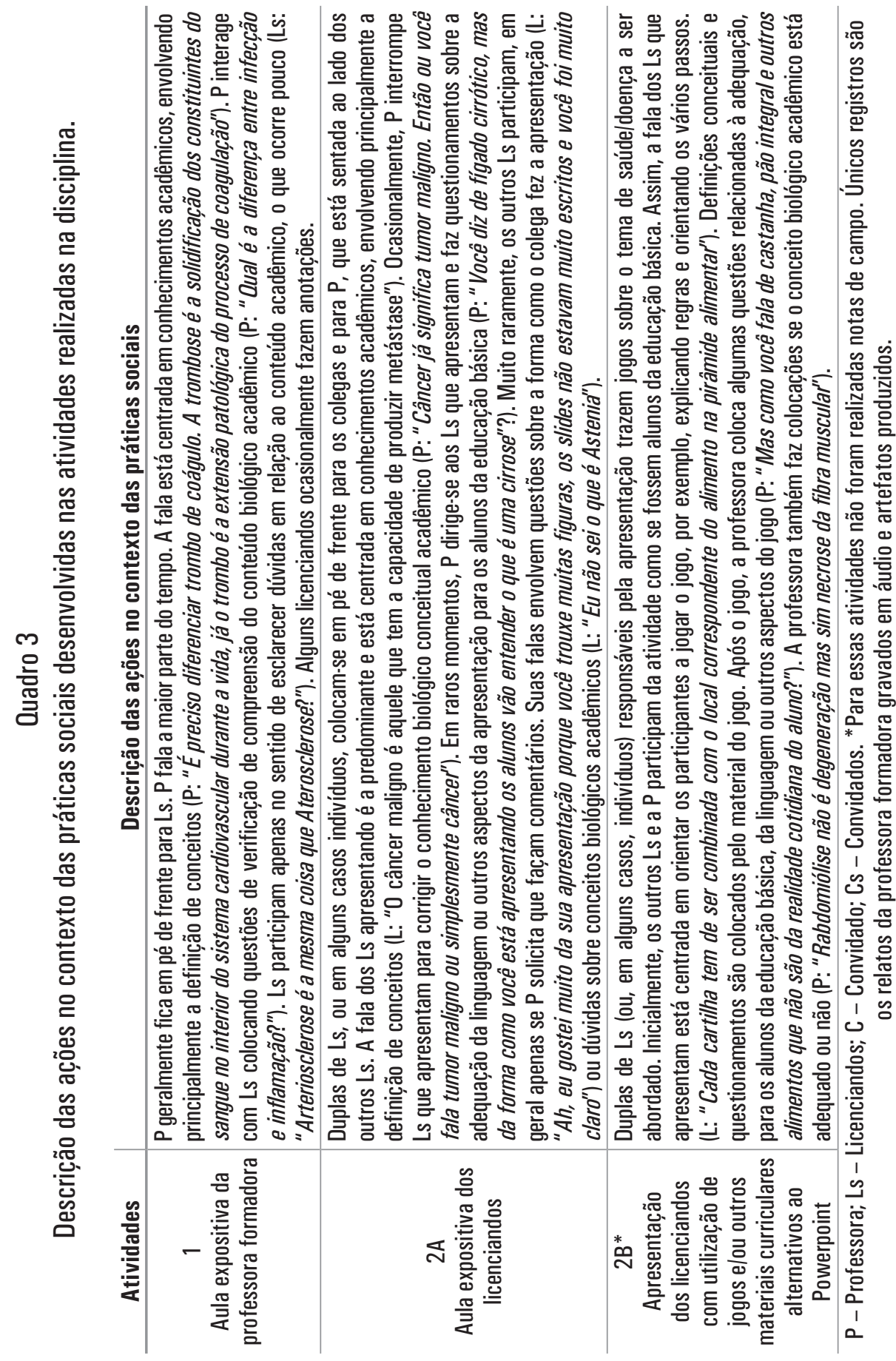




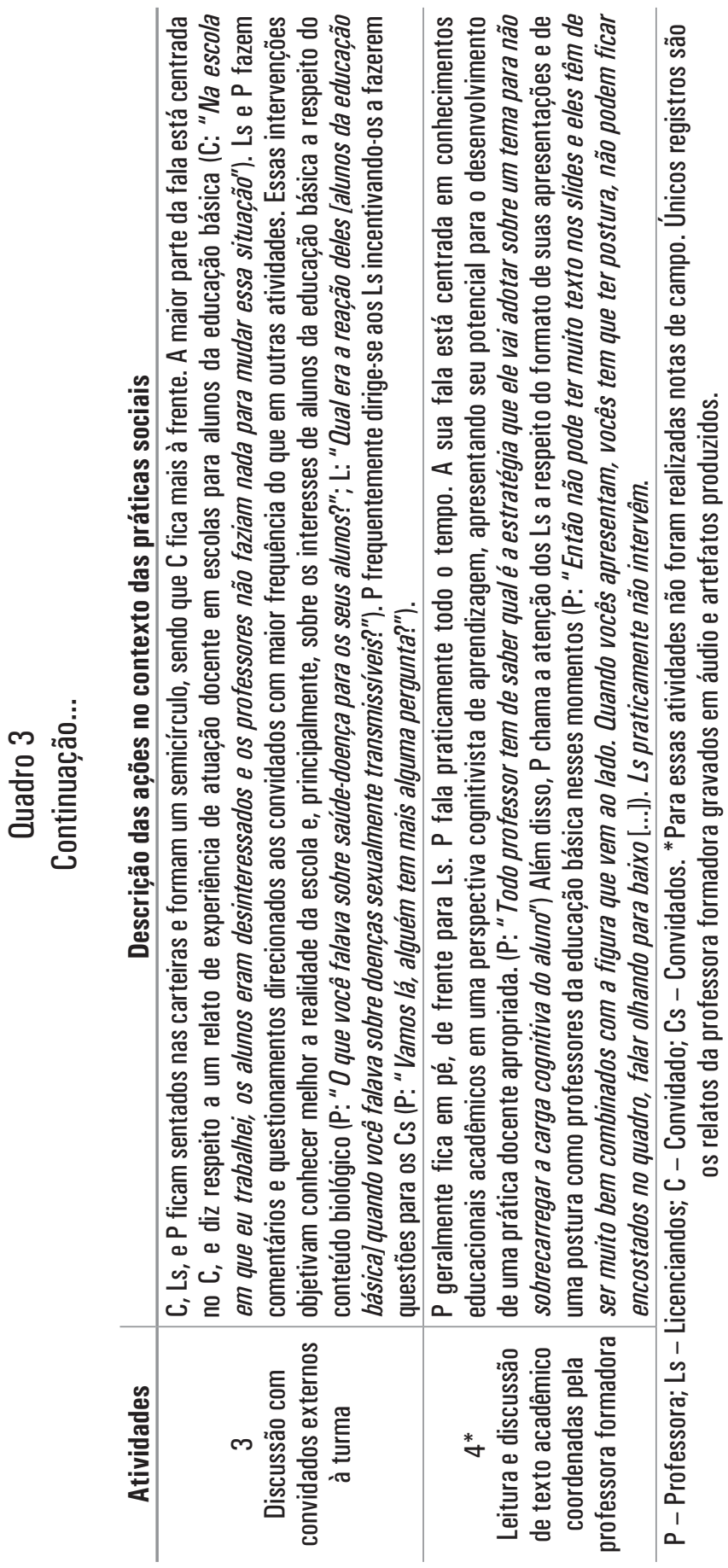


Percebe-se nessas, e em outras falas, uma significativa preocupação por parte de Maria com o domínio de termos, conceitos e estruturas biológicas pelos licenciandos como um pré-requisito para a realização de suas apresentações. Ainda mais relevante, não foi possível identificar, nessas atividades, menção explícita a outras formas de conhecimento, tais como aquelas do campo educacional e, em especial, conhecimentos relacionados à escola e/ou aos alunos, ou ao ensino de Ciências. Ou seja, nessas atividades, o conhecimento biológico é tomado como central na formação de professores, fazendo com que os sentidos das relações entre teoria e prática passem, quase que exclusivamente, por esse conhecimento. Nessa perspectiva, os sentidos de prática, por exemplo, são produzidos na relação com os conteúdos de Patologia, se afastando de perspectivas que o aproximariam da escola e, portanto, de expressões como "prática docente" ou "prática pedagógica". Além disso, o principal protagonista nessas atividades é a professora formadora, centralizando a organização das ações e, consequentemente, a produção de sentidos na universidade. Podemos representar os sentidos das relações entre teoria e prática na atividade 1 de acordo com a Figura 2.

\section{Figura 2}

Relações entre teoria e prática na atividade 1. As elipses representam os atores sociais protagonistas; os retângulos ao longo da seta, os conhecimentos mobilizados; e o retângulo no espaço entre as setas, os artefatos utilizados.

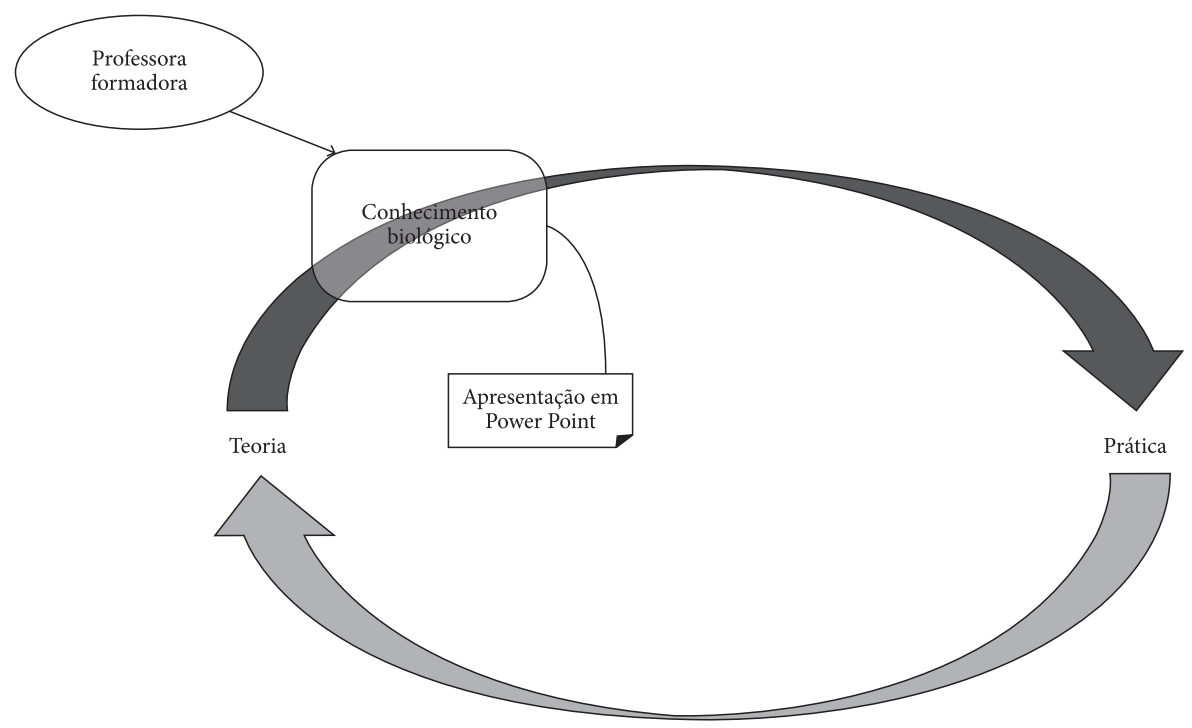


A categoria atividade 2 engloba um conjunto de aulas que foram realizadas a partir das apresentações dos alunos. Nesse caso, cada um dos licenciandos preparava aulas para os estudantes da educação básica e as desenvolvia no espaço da universidade, com a participação de seus colegas e da professora formadora. Conforme Maria diz: "no laboratório de ensino [...], eles apresentam suas aulas como se estivessem simulando uma aplicação dessas aulas na escola" ${ }^{\prime 1}$. Nesse caso, os protagonistas passam a ser os licenciados. A atribuição desse protagonismo está associada à exigência de que as aulas sejam voltadas para a educação básica, o que não era esperado quando a professora formadora era a principal protagonista (atividade 1). Tal exigência, no entanto, não tira a centralidade da universidade na produção dos sentidos acerca das relações entre teoria e prática, uma vez que os licenciandos carregam significados hegemonicamente informados pelos conhecimentos biológicos, ainda que com certa interação com o universo escolar.

Para melhor entender esse último aspecto, as ações desenvolvidas nesse grupo foram subdivididas em A e B, conforme os artefatos utilizados pelos licenciandos para realizá-las. Assim, na categoria atividade 2A foram incluídas as apresentações dos licenciandos que estavam centradas no uso de slides no Power Point e Data Show. Por meio da análise dos relatos da docente e dos materiais curriculares produzidos por esses alunos, percebemos, do mesmo modo, que na atividade 1 havia uma grande ênfase no conhecimento biológico na produção de sentidos acerca das relações entre teoria e prática. Porém, surgem, muito raramente, algumas referências à escola ou aos alunos, mesmo que ocorrendo de modo superficial e sucinto, com breve menção a relações entre necessidades de aprendizado do conteúdo biológico e a "vida do estudante". Por outro lado, nessas atividades não houve referências a estudos e pesquisas sobre o ensino desse conteúdo ou, então, ao ensino de Ciências de forma mais ampla.

Entretanto, nessa categoria podemos destacar a exigência da professora formadora de que os licenciandos deem certa atenção a um conhecimento do alunado. Em alguns relatos, por exemplo, a docente faz críticas às apresentações com relação à "adequação do conteúdo biológico para o público”, os estudantes da educação básica. Dois momentos de avaliação da apresentação dos alunos evidenciam essa preocupação da formadora. Primeiro, quando Maria considera uma falha na apresentação do licenciando: "[...] o aluno não se preocupou com o público alvo. [...] ele preparou 
a aula como se fosse para os colegas"12. Segundo, quando ela avalia um aspecto positivo na apresentação de outro licenciando: "a aluna tinha uma dinâmica de falar que era bem adequada à escola"13.

Os sentidos das relações entre teoria e prática na atividade $2 \mathrm{~A}$ podem ser representados de acordo com a Figura 3.

A categoria atividade 2B é composta pelas ações dos licenciandos que utilizaram jogos ou outros materiais curriculares. A utilização desses artefatos para o ensino nos permite entender outro conhecimento que parece estar participando da produção de sentidos acerca das relações entre teoria e prática, o qual se refere ao lúdico como meio de favorecer o aprendizado. Nesse sentido, é conferido significativo crédito, por parte de Maria, à utilização desses recursos nas apresentações dos licenciandos. A professora formadora afirma: "Ela fez. um joguinho que faria com que as crianças fixassem aquilo que ela passou, o assunto da aula. [...] o jogo ajuda a fixar 0 assunto da aula"14. Todavia, como também se pode observar no trecho anterior, percebemos que a ideia central é a da utilização do jogo como

Figura 3

Relações entre teoria e prática na atividade 2A. As elipses representam os atores sociais protagonistas; os retângulos ao longo da seta, os conhecimentos mobilizados; e o retângulo no espaço entre as setas, os artefatos utilizados.

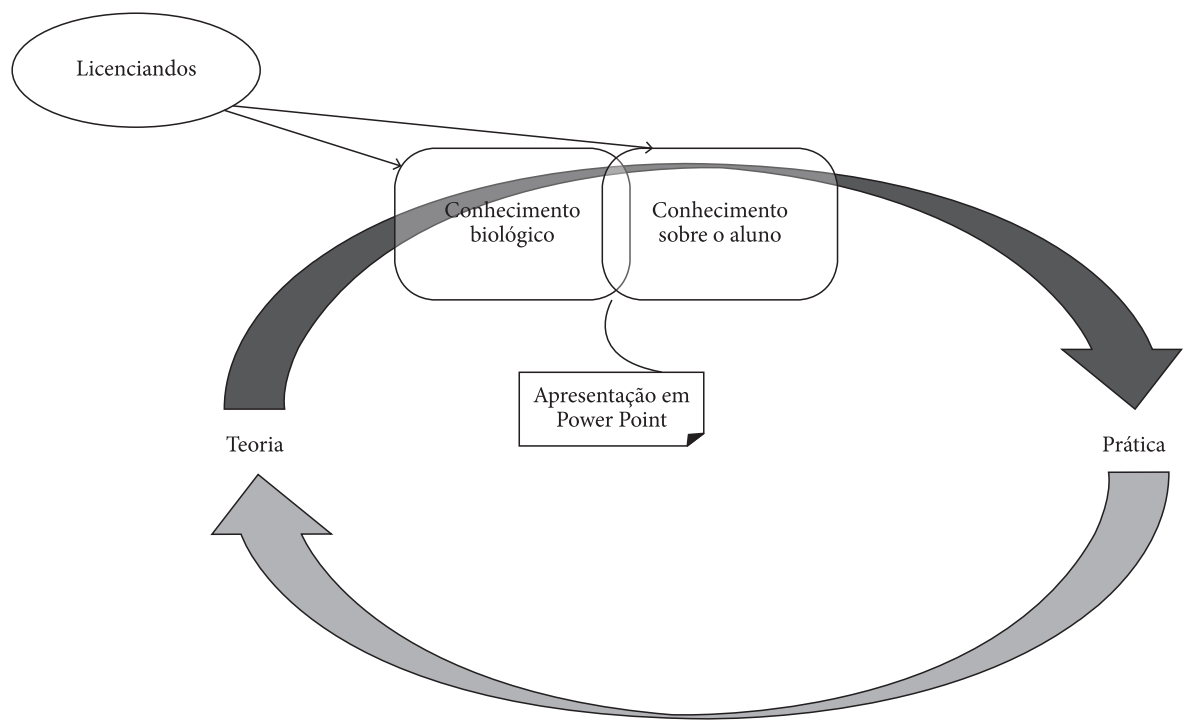


uma ferramenta para memorização dos conteúdos biológicos. Em outros termos, o jogo é visto como uma técnica para o ensino do conteúdo biológico. Tal visão pode também ser percebida na análise dos artefatos produzidos pelos alunos, uma vez que os dois jogos confeccionados pelos licenciandos - Jogo da Memória e um Bingo - trataram de uma combinação entre elementos de sorte com a memorização de conteúdos biológicos. Os sentidos das relações entre teoria e prática na atividade $2 \mathbf{B}$ podem ser representados de acordo com a Figura 4.

Em comparação com a categoria atividade 1, percebemos a presença de novos conhecimentos nas categorias atividade $2 \mathbf{A}$ e atividade $2 \mathbf{B}$. Assim, ainda que nessas últimas o conhecimento biológico seja hegemônico na produção de sentidos acerca das relações entre teoria e prática, ele não é suficiente, nas palavras da professora formadora, para se "dar aula" ou "aplicar esses conhecimentos". Reconhece-se, então, uma necessidade de "adaptação" do conhecimento biológico, que deve ser realizada mediante um conhecimento do aluno e de técnicas educacionais, ainda que o primeiro não

\section{Figura 4}

Relações entre teoria e prática na atividade 2B. As elipses representam os atores sociais protagonistas; os retângulos ao longo da seta, os conhecimentos mobilizados; e o retângulo no espaço entre as setas, os artefatos utilizados.

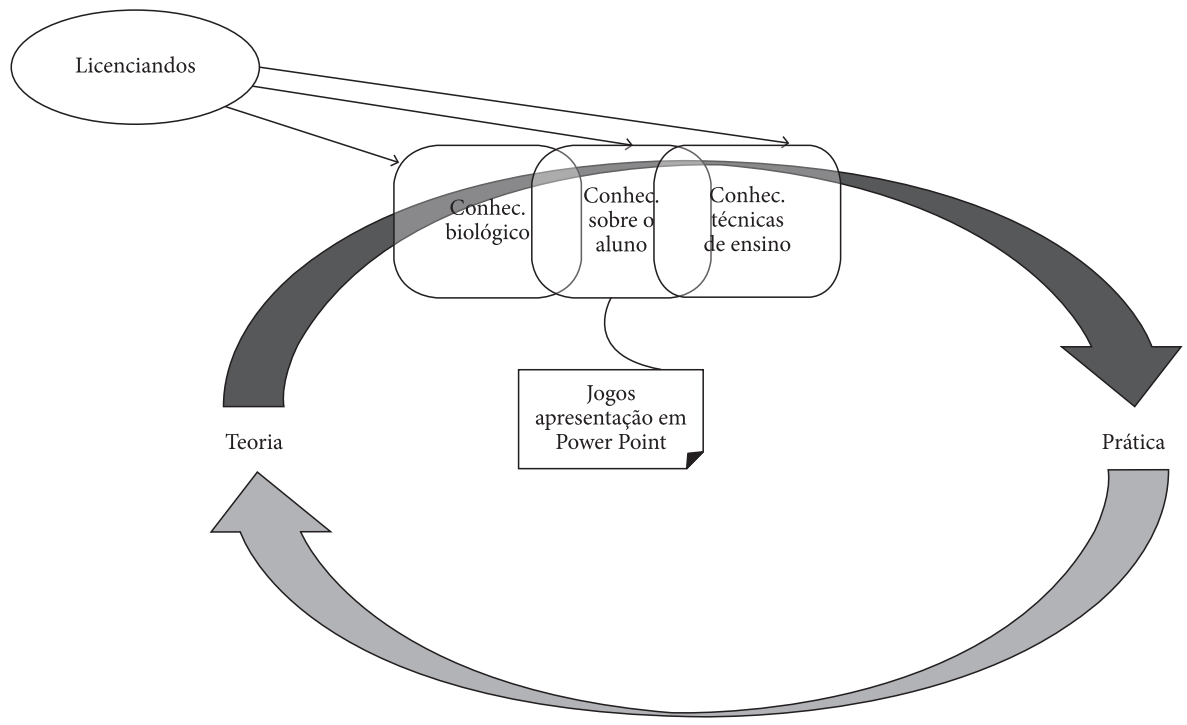


saia do centro das ações formativas. Essas transformações - consideravelmente sutis - nos conhecimentos que circulam nas categorias atividade $2 \mathrm{~A}$ e atividade $2 \mathbf{B}$ forjam sentidos das relações entre teoria e prática que, embora ainda fortemente associados ao conhecimento biológico, são impactados por conhecimentos da e sobre a escola que são mediados pelos licenciandos.

A categoria atividade 3 compreende os grupos de discussão que, no âmbito da disciplina acadêmica Laboratório de Ensino de Patologia, contavam com a presença de outros atores sociais, convidados pela professora formadora. De acordo com ela, a realização dessas ações tinha como objetivo entender "[...] como está sendo abordado [determinado conteúdo biológico] na escola? Coisas diferentes acontecem". Para Maria, se "[...] en vou falar sobre [tal conteúdo biológico] eu preciso analisar o perfil da escola. Que tipo de alunos eu tenho ali? Como eles estão se comportando?"15. Nesse contexto, os convidados servem para veicular conhecimentos que, segundo a professora, permitem que os licenciandos conheçam o aluno da educação básica. Podemos dizer que os sentidos das relações entre teoria e prática são produzidos em meio a explanações e debates voltados para a caracterização de aspectos sociais, culturais e econômicos dos alunos e de seus interesses frente ao conteúdo biológico. Observe um trecho das anotações de nosso caderno de campo durante esse tipo de atividade:

Esta aula é praticamente centrada nas falas da professora formadora e das convidadas. As poucas discussões que ocorrem têm como foco o entendimento de quem são esses alunos. E quais são os seus interesses a respeito de alguns dos conteúdos selecionados para o ensino nesta disciplina ${ }^{16 .}$

Vale ressaltar que ainda assim as ações dos convidados categorizadas na atividade 3 estão localizadas na universidade e, preferencialmente, na produção do conhecimento biológico. Um deles foi uma pesquisadora na área das ciências biológicas desenvolvendo, também, estudos que investigavam as dificuldades de aprendizagem de estudantes em Matemática. Segundo a convidada, tais

[...] dificuldades são geralmente associadas com outras dificuldades de aprendiragem atribuídas a fatores genéticos, associados a componentes ambientais (drogas); QI; e dificuldade crônica de aprendizagem. [...] um dos objetivos de sua pesquisa é criar jogos para tentar auxiliar essas crianças $^{17}$. 
Outra convidada também era pesquisadora na área das ciências biológicas, muito embora já houvesse atuado como professora na educação básica durante um curto período de tempo. Esta segunda convidada faz o seguinte relato: "[...] en fui proibida de falar sobre educaşão sexual com alunos da sexta série porque a direção da escola não considerou apropriado" ${ }^{17}$. Por fim, o último convidado foi também um biólogo dessa instituição de ensino superior, muito embora atuasse, também, como diretor de uma escola pública ${ }^{18}$. Em todos esses momentos, percebemos uma preocupação em reconhecer a presença de outros fatores externos à sala de aula que podem interferir no trabalho do professor. O último desses convidados chama a atenção, por exemplo, para a adoção de "assuntos polêmicos, como o uso de drogas" como uma opção "[...] complicada, pois há intimidação de traficantes que interferem no trabalho do professor [...]"20.

No que se refere à produção de sentidos acerca das relações entre teoria e prática, percebemos que, na categoria atividade 3 a inserção de outros conhecimentos nas ações formativas desloca ainda mais o conhecimento biológico do centro do processo. Tal movimento, no entanto, não é suficiente para "enfraquecê-lo", uma vez que, também nesse caso, os sujeitos "autorizados" a falar desses outros conhecimentos são também filiados à universidade e, nesse contexto, ao conhecimento biológico. Afinal, não foi convidado qualquer profissional vinculado à área da Educação como campo de pesquisa. Assim, ao que parece, aqueles que falam da escola pertencem à universidade, produzindo sentidos das relações entre teoria e prática que, mais uma vez, estão informados, em grande parte, pelo conhecimento biológico. Esses sentidos podem ser representados de acordo com a Figura 5.

Por fim, a categoria atividade 4 , constituída por apenas uma aula, foi a única que não estava prevista no planejamento da professora formadora ${ }^{21}$. Nessa aula, Maria distribuiu um texto para que os estudantes lessem e depois discutissem. O texto abordava a teoria da carga cognitiva e, de acordo com ela, foi utilizado com o propósito de

[...] maximizar a aprendizagem dos alunos. [...] Uma tentativa de chamar a atenção para quando [os licenciandos] trabalham com os alunos em sala de aula, [eles] devem estar atentos ao como você apresenta. [...] como, mostrar imagens e texto juntos. [...] Gestos, principalmente para crianças, ajudam a reduzir a carga cognitiva $[. . .]^{22}$. 
Figura 5

Relações teoria e prática na atividade 3. As elipses representam os atores sociais protagonistas; os retângulos ao longo da seta, os conhecimentos mobilizados; e 0 retângulo no espaço entre as setas, os artefatos utilizados.

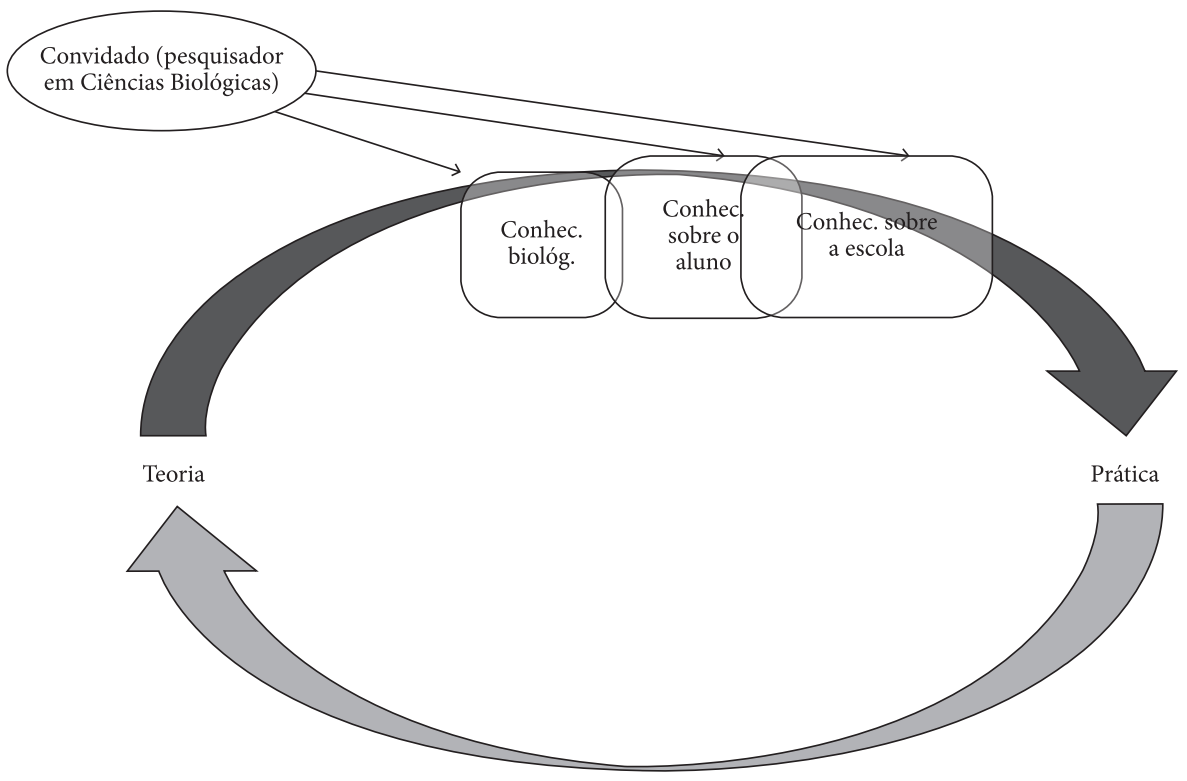

Esse é o único momento no qual a professora formadora escolhe dialogar de forma explícita com conhecimentos da área da Educação, mais especificamente com aqueles relacionados à aprendizagem e à cognição. Tais conhecimentos parecem agregar um caráter técnico aos sentidos das relações entre teoria e prática, uma vez que a atenção maior parece estar na forma como se ensina, apoiando-se em referencial associado a uma perspectiva cognitivista.

Essa preocupação da professora formadora com a utilização de conhecimentos voltados para um caráter técnico do ensino pode ser observada em outro relato, em que ela faz reflexões sobre um planejamento da disciplina acadêmica para o próximo semestre: "Eu acho que vou fazer uma primeira aula, no próximo semestre, sobre o professor em sala de aula: carga cognitiva, gestos, posturas. Quando eu entrar [no conteúdo biológico], vou chamar a atenção para essas coisas"23. Isso aparece, também, na seguinte crítica que Maria faz à apresentação de um aluno: "Ele demonstrou falta de interesse pela licenciatura. [...] Aula somente 
expositiva. Também não tem postura como professor. É sem empolgação. Professor tem que ter postura, confiança [...]"24. Nessa categoria, a professora formadora volta a estar no centro das ações, ainda que veiculando um outro conhecimento científico que não o biológico, em um movimento de produção de sentidos que, ainda assim, mantém a universidade e seus atores sociais como aqueles autorizados a falar sobre e para a escola. Os sentidos das relações entre teoria e prática na atividade 4 podem ser representados de acordo com a Figura 6.

\section{CONSIDERAÇÕES FINAIS}

A natureza dos conhecimentos envolvidos na docência e as relações entre teoria e prática na formação de professores têm sido amplamente discutidas e examinadas na literatura. Tais pesquisas têm contribuído para uma visão mais crítica dos currículos de formação inicial de professores. Porém, esses estudos estão frequentemente voltados para a análise de

Figura 6

Relações entre teoria e prática na atividade 4. As elipses representam os atores sociais protagonistas; os retângulos ao longo da seta, os conhecimentos mobilizados; e o retângulo no espaço entre as setas, os artefatos utilizados.

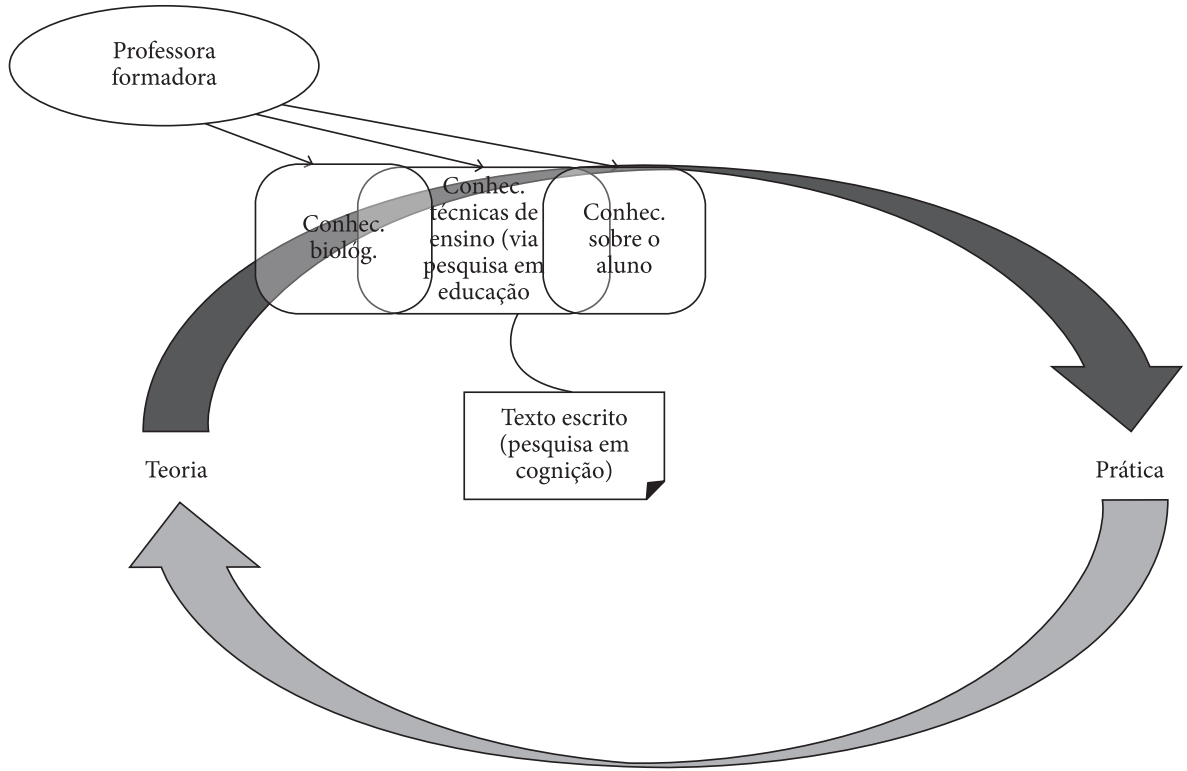


documentos e de entrevistas, sendo que pouco se sabe sobre como se dá o processo de construção desses sentidos no contexto da sala de aula de cursos de licenciatura.

Nesse estudo, ao examinarmos aspectos das práticas sociais em uma disciplina acadêmica, foi possível problematizar de forma mais aprofundada as formas como são construídos diversos sentidos de teoria e prática na formação inicial de professores. Paralelamente foi possível delinear um retrato menos monolítico dessas práticas, conhecendo sua diversidade e, consequentemente, identificando-se possibilidades de ação para desafiar e resistir a tendências que engessam a formação docente ao promoverem um distanciamento entre teoria e prática.

Quando nos voltamos para a formação de professores que se realiza em espaços acadêmicos nos quais os professores formadores não possuem uma formação específica para a docência, é relativamente comum a ocorrência de aulas expositivas centradas no domínio do conteúdo específico. Nessas aulas, a preocupação está em instrumentalizar os licenciandos para eles façam uma espécie de aplicação desses conteúdos nas escolas. Em nossa pesquisa, identificamos algumas práticas da professora Maria que acabam por fixar sentidos consoantes com tradições advindas do modelo da racionalidade técnica. Acreditamos que, entre outros aspectos, profissionais como ela adotam essas práticas por se encontrarem imersos em uma cultura na qual a primazia do conhecimento específico já está cristalizada em práticas cotidianas. Nesse contexto, tais professores acabam se preocupando pouco com as relações que o conhecimento científico estabelece com outras formas de conhecimento, sobretudo os escolares e educacionais.

Todavia, foi possível identificar nas práticas promovidas na disciplina acadêmica investigada que essa professora formadora, para além do conteúdo biológico, agregava outras formas de conhecimento em sua aula. Entendemos que essas práticas têm potencial para subverter sentidos de relação teoria e prática ainda hegemônicos na formação de professores. Afinal, mesmo mantendo o conhecimento biológico como central, Maria reconheceu a importância de conhecimentos acerca dos alunos e da escola. Além disso, a professora deu atenção para formas de mediar o processo de ensino-aprendizagem, ainda que em perspectiva mais centralmente afinada com o modelo da racionalidade técnica. É nesse contexto que ela trouxe para a sala de aula, por exemplo, conhecimentos da área da Educação, por meio da discussão de teorias cognitivistas. Apesar de uma ausência quase 
completa de diálogos com a pesquisa em Educação em Ciências e com a Formação de Professores, esse movimento no sentido de reconhecer o conhecimento acadêmico acerca da aprendizagem é significativo quando ocorre em uma disciplina acadêmica produzida em um Instituto de Ciências Biológicas.

Em nossa perspectiva, no entanto, para que relações entre teoria e prática possam ser significativamente produzidas em disciplinas acadêmicas dessa natureza na direção desejada, seria necessário um aprofundamento em áreas do conhecimento que problematizam questões sobre os alunos, a escola e a atuação dos professores, deslocando-se o foco do ensino como transmissão de conhecimentos para uma educação em Ciências como prática contextualizada na escola. Nesse sentido, torna-se imperativo que os formadores de professores fiquem atentos a como se criam hierarquias entre as formas de conhecimento que colocam a escola, frequentemente, em posição inferior em relação à universidade. É claro que, no caso investigado, percebemos esforços no sentido de trazer a escola para o espaço da sala de aula da disciplina acadêmica. Porém, ainda circulam, de modo hegemônico, conhecimentos sobre a (e não da) escola. Os atores sociais bem como artefatos produzidos e utilizados tampouco pertencem à escola. Ao contrário, eles têm sua referência ancorada na universidade. Ainda assim, nossas análises das diferentes atividades desenvolvidas na disciplina acadêmica nos permite perceber o quanto sentidos mais complexos de relações teoria e prática foram se constituindo com a entrada de determinados conhecimentos sobre os alunos e a escola no processo. Nesses movimentos fomos evidenciando aproximações sutis do modelo da racionalidade prática quando certas abordagens de ensino de conteúdos biológicos diante de uma determinada realidade escolar foram discretamente interrogadas. Fomos, então, observando declarações e ações que revelaram uma atenção para com aspectos como a linguagem adotada, os interesses dos alunos frente aos conteúdos e a proposição de atividades que dialogassem com a faixa etária dos alunos.

No entanto, não identificamos na análise tanto das entrevistas quanto das observações em sala de aula e dos artefatos, referências explícitas à produção de sentidos das relações teoria e prática mais fortemente ancorados no modelo da racionalidade crítica. Afinal, ainda que tenhamos percebido certa atenção para com a importância das questões socioeconômicas na atuação do professor na educação básica, não evidenciamos que essas fossem centrais na formulação de sentidos mais explicitamente voltados para uma 
modificação da realidade mediante ações orientadas e bem fundamentadas em princípios de justiça social. Nesse contexto, argumentamos em favor da criação de condições para que, ao longo da formação inicial, os licenciandos das Ciências Biológicas protagonizassem atividades envolvendo uma multiplicidade maior de objetivos, produzidos em meio a diversos tipos de conhecimento. Consideramos que caminhar nessa direção representa ir de encontro a concepções que ainda colocam o professor como um mero técnico que aplica o conhecimento produzido por outros, assim como daquelas que o percebem de forma acrítica e descontextualizada, investindo na produção de outros sentidos para a formação inicial de professores na área. 


\section{REFERÊNCIAS}

ANDRADE, E. P. et al. A dimensão prática na formação inicial docente em Ciências Biológicas e em História: modelos formativos em disputa. Ensino em Revista, Uberlândia, v. 12, n. 1, p. 7-19, 2004.

ANDRADE, E. P. Um Trem Rumo às Estrelas: A Oficina de Formação Docente Para o Ensino de História (O curso de História da FAFIC). 2006. Tese (Doutorado em Educação)Universidade Federal Fluminense, Niterói, 2006.

ANDRÉ, M. (Org.). Formação de professores no Brasil (1990-1998). Brasília: MEC, INEP, Comped, 2002. p. 1-34.

BALL, S. J.; BOWE, R. The Policy Processes and the Processes of Policy. In: BOWE, R.; BALL, S. J.; GOLD, A. (Orgs.). Reforming Education and Changing Schools: Case Studies in Policy Sociology. Londres; Nova York: Routledge, 1992. p. 6-23.

BLOOME, D. On discourse analysis in classrooms: approaches to language and literacy research. New York: Teachers College Press, 2008.

BORGES, C. Saberes docentes: diferentes tipologias e classificações de um campo de pesquisa. Educação \& Sociedade, São Paulo, v. 22, n. 74, p. 59-75, 2001. http://dx.doi. org/10.1590/S0101-73302001000100005

BRASIL. Ministério da Educação. Parecer CNE/CP no 9/2001, de 8 de maio de 2001. Estabelece as Diretrizes Curriculares Nacionais para a Formação de Professores da Educação Básica, em nível superior, curso de licenciatura, de graduação plena. Diário Oficial da República Federativa do Brasil, Brasília, DF, maio 2001a.

BRASIL. Ministério da Educação. Parecer CNE/CP nº 28/2001, de 2 de outubro de 2001. Dá nova redação ao Parecer CNE/CP 21/2001 e discorre sobre a duração e a carga horária dos cursos de Formação de Professores da Educação Básica, em nível superior, curso de licenciatura, de graduação plena. Diário Oficial da República Federativa do Brasil, Brasília, DF, out. 2001b.

BRASIL. Ministério da Educação. Resolução CNE/CP no 1/2002, de 18 de fevereiro de 2002. Institui as Diretrizes Curriculares Nacionais para a Formação de Professores da Educação Básica, em nível superior, curso de licenciatura, de graduação plena. Diário Oficial da República Federativa do Brasil, Brasília, DF, 04 mar. 2002a. Seção 1, p. 8.

BRASIL. Ministério da Educação. Resolução CNE/CP no 2/2002, de 18 de fevereiro de 2002. Institui a duração e a carga horária dos cursos de Formação de Professores da Educação Básica, em nível superior. Diário Oficial da República Federativa do Brasil, Brasília, DF, 04 mar. 2002b. Seção 1, p. 9.

BRZEZINSKI, I. (Org.). Formação de profissionais da educação (1997-2002). Brasília: Ministério da Educação, INEP, 2006. p. 1-52.

CASTANHEIRA, M. L. Aprendizagem contextualizada: discursos e inclusão na sala de aula. 2. ed. Belo Horizonte: Ceale, Autêntica, 2004.

DELIZOICOV, D.; ANGOTTI, J. A. P.; PERNAMBUCO, M. M. Ensino de Ciências: fundamentos e métodos. São Paulo: Cortez, 2003. 364 p. 
DINIZ-PEREIRA, J. E. As licenciaturas e as novas políticas educacionais para formação docente. Educação \& Sociedade, São Paulo, n. 68, p. 109-125, 1999. http:/ /dx.doi.org/10.1590/ S0101-73301999000300006

DINIZ-PEREIRA, J. E. A prática como componente curricular na formação docente. In: HARMUCH, R. A.; SALEH, P. B. O. (Orgs.). Estudos da linguagem e formação docente. Campinas: Mercado de Letras, 2011. p. 99-115.

DINIZ-PEREIRA, J. E. Paradigmas contemporâneos da formação docente. In: SOUZA, J. V. A. (Org.). Formação de Professores para a Educação básica: dez anos da LDB. Belo Horizonte: Autêntica, 2007. p. 253-263.

FERREIRA, M. S.; VILELA, M. L.; SELLES, S. E. Formação docente em Ciências Biológicas: estabelecendo relações entre a prática de ensino e o contexto escolar. In: SELLES, S. E.; FERREIRA, M. S. (Orgs.). Formação docente em Ciências: memórias e práticas. Niterói: EDUFF, 2003. p. 29-46.

FERREIRA, M. S. A História da Disciplina Escolar Ciências no Colégio Pedro II (1960-1980). 2005. Tese (Doutorado em Educação)-Universidade Federal do Rio de Janeiro, Rio de Janeiro, 2005. FERREIRA, M. S. Investigando os rumos da disciplina escolar Ciências no Colégio Pedro II (1960-1970). Educação em Revista, Belo Horizonte, v. 45, p. 127-144, 2007. http:/ /dx.doi. org/10.1590/S0102-46982007000100008

GATTI, B. A.; BARRETO, E. S. (Coords.). Professores do Brasil: impasses e desafios. Brasília: UNESCO, 2009. 294 p.

GAUTHIER, C. et al. Por uma teoria da Pedagogia: pesquisas contemporâneas sobre o saber docente. Ijuí: Ed. Unijuí, 1998. 457 p. (Coleção Fronteiras da Educação).

GIBBS, G. Análise de dados qualitativos. Tradução de Ronaldo Cataldo Costa. Porto Alegre: Artmed, 2009. 198 p.

GREEN, J.; DIXON, C.; ZAHARLICK, A. A etnografia como uma lógica de investigação. Tradução de Adail Sebastião Rodrigues Júnior e Maria Lúcia Castanheira. Educação em Revista, Belo Horizonte, v. 42, p. 13-79, 2005.

KELLY, G. J. Discourse in Science Classrooms. In: ABELL, S. K.; LEDERMAN, N. G. Handbook of Research on Science Education. London: U.K. LEA, 2007.

KELLY, G. J.; CRAWFORD. T. An ethnographic investigation of the discourse processes of school science. Science Education, Salem, v. 81, n. 5, p. 533-559, 1997. http://dx.doi. org/10.1002/(SICI)1098-237X(199709)81:5<533::AID-SCE3>3.0.CO;2-B

LINCOLN, Y. S.; GUBBA, E. G. Naturalistic Inquiry. Beverly Hills: SAGE Publications 1985. MALDANER, O. A.; ZANON, L. B.; AUTH, M. A. Pesquisa sobre educação em ciências e formação de professores. In: SANTOS, F. M. T.; GRECA, I. M. (Orgs.). A pesquisa em Ensino de Ciências no Brasil e suas Metodologias. Ijuí: Ed. Unijuí, 2006 (Coleção Educação em Ciências).

MARCELO, C. Pesquisa sobre formação de professores: o conhecimento sobre aprender a ensinar. Revista Brasileira de Educação, Rio de Janeiro, n. 9, p. 51-75, set./dez. 1998.

NÓVOA, A. Os professores e sua formação. Lisboa: Dom Quixote. 1997.

PINO, A. As marcas do humano: Às origens da constituição cultural da criança na perspectiva de Lev S. Vigostki. São Paulo: Cortez, 2005. 
PUTMAN, R. T.; BORKO, H. What do new views of knowledge and thinking have to say about research on teacher learning? Educational Researcher, Washington, v. 29, n. 1, p. 4-15, 2000. http://dx.doi.org/10.3102/0013189X029001004

SANTOS, L. L. C. P. Paradigmas que orientam a formação docente. In: SOUZA, J. V. A. (Org.). Formação de Professores para a Educação básica: dez anos da LDB. Belo Horizonte: Autêntica, p. 235-252, 2007.

SCHÖN, D. The reflective practitioner. New York: Basic Books, 1983.

SCHÖN, D. Formar professores como profissionais reflexivos. In: NÓVOA, A. (Org.). Os professores e sua formação. Lisboa: Don Quixote, 1997.

SCHÖN, D. Educando o profissional reflexivo. Porto Alegre: Artmed. 2000.

SELLES, S. E.; FERREIRA, M. S. Saberes docentes e disciplinas escolares na formação de professores em Ciências e Biologia. In: SELLES, S. E. et al. (Orgs.). Ensino de Biologia: histórias, saberes e práticas formativas. Uberlândia: EdUFU, 2009. p. 49-69.

SHULMAN, L. S. Those who understand: Knowledge growth in teaching. Educational Researcher, Washington, v. 15, n. 2, p. 4-14, 1986.

SHULMAN, L. S. Knowledge and teaching: foundations of the new reform. Boston: Harvard Education Review. 1987.

SPRADLEY, J. P. Participant Observation Harcourt Brace Jovanovich College Publishers. Orlando, 1980. TARDIF, M. Saberes docentes e Formação profissional. Petrópolis: Editora Vozes, 2004. 325 p. TERRAZZAN, E. A. Inovação Escolar e Pesquisa sobre formação de professores. In: NARDI, R. (Org.). A pesquisa em Ensino de Ciências no Brasil: alguns recortes. São Paulo: Escrituras Editora, 2007.

TERRERI, L. Politicas curriculares para a formação de professores em Ciências Biológicas: investigando sentidos de prática. 2008. Dissertação (Mestrado em Educação)-Universidade Federal do Rio de Janeiro, Rio de Janeiro, 2008.

ZEICHNER, K. The new scholarship in Teacher Education. Educational Researcher, Washington, v. 28. p. 4-15, 1999. http://dx.doi.org/10.3102/0013189X028009004 ZEICHNER, K. Formação de professores para a justiça social em tempos de incerteza e desigualdades crescentes. In: DINIZ-PEREIRA, J. E.; ZEICHNER, K. M. (Orgs.). Justiça Social: Desafio para a Formação de Professores. Belo Horizonte: Autêntica, 2008. p. 11-34. ZEICHNER, K.; LISTON, D. Reflective teaching: an introduction. Mahwah: Lawrence Erlbaum Associates, 1996.

\section{NOTAS}

${ }^{1} \mathrm{O}$ texto foi produzido no âmbito do projeto de pesquisa intitulado Sentidos das relações entre teoria e prática em cursos de formação de professores em Ciências Biológicas: entre histórias e políticas de currículo, desenvolvido com o apoio do CNPq.

2 Tal fato é exemplificado por trabalhos como os de Carlos Marcelo (1998), Marli André (2002) e Íria Brzezinski (2006). 
${ }^{3}$ Considerando "[...] o número de alunos matriculados no ensino fundamental proporcionalmente ao contingente de crianças e adolescentes na faixa etária correspondente ou próxima [...]" (GATTI; BARRETO, 2009, p. 11).

${ }^{4}$ Como exemplo desses movimentos podemos destacar a I Conferência Brasileira de Educação em São Paulo em 1980, que culminou com a instalação do Comitê Nacional Pró-Formação do Educador e do Encontro Nacional do Projeto de Reformulação dos Cursos de Preparação de Recursos Humanos para Educação, em Belo Horizonte, em 1983, culminando na criação da Comissão Nacional de Reformulação dos Cursos de Formação do Educador (CONARFE) (DINIZ-PEREIRA, 2006).

${ }^{5}$ Estamos nos referindo aos pareceres CNE/CP 9/2001 e CNE/CP 28/2001 e às resoluções CNE/CP 1/2002 e CNE/CP 2/2002.

${ }^{6}$ É preciso ainda ressaltar que a relação entre organismos internacionais, com destaque para o Banco Mundial, e modelos de formação de professores não se limitou a propostas fundamentadas no modelo da racionalidade técnica. Pois, segundo Diniz-Pereira (2007, p. 259), essas organizações, incluindo o já citado Banco Mundial, "[...] têm recentemente se apropriado do discurso da racionalidade prática para manter seu controle sobre os programas de formação de professores [...]".

${ }^{7}$ Esse curso de licenciatura é composto por 3075 horas, integralizadas em 9 semestres no curso diurno e em 10 no curso noturno. O curso estrutura-se da seguinte forma: 2025 horas são atividades acadêmicas de natureza teórica, abrangendo conhecimentos na área das ciências biológicas, educação e áreas das ciências exatas e ciências da terra; 210 horas de atividades acadêmicas científico cultural, 435 horas de atividades relacionadas a PCC e 405 horas de estágio curricular supervisionado. Em relação ao PCC, a Faculdade de Educação é responsável por 120 horas de atividades, as quais são desenvolvidas em três disciplinas de Análise Crítica da Prática Pedagógica e duas disciplinas de Didática do Ensino de Ciências e de Biologia. O restante das atividades de PCC é de responsabilidade do Instituto de Ciências Biológicas, envolvendo disciplinas de Laboratório de ensino de conteúdos específicos como Ecologia, Zoologia, Patologia, Parasitologia etc, sendo algumas dessas disciplinas optativas e outras obrigatórias. Cabe destacar também, que esse curso de Licenciatura possuía atividades acadêmicas comuns ao Bacharelado na mesma instituição. Esse conjunto de disciplinas comuns foi denominado de Núcleo Fixo e era composto por 1530 horas.

${ }^{8}$ A análise de Kelly e Crawford foi gerada a partir de orientação de Spradley (1980), visando caracterizar "visões de ciências da natureza" presentes em uma sala de aula da disciplina Ciências da Natureza da educação básica.

${ }^{9}$ Entrevista realizada em 26/4/2011.

${ }^{10}$ Entrevista realizada em 26/5/2011.

${ }^{11}$ Entrevista realizada em 9/6/2011.

12 Entrevista realizada em 19/4/2011.

${ }^{13}$ Entrevista realizada em 12/4/2011. 
${ }^{14}$ Entrevista realizada em 19/5/2011.

${ }^{15}$ Entrevista realizada dia 14/6/2011.

16 Anotações de caderno de campo de observação realizada 22/3/2011

17 Anotações de caderno de campo de observação realizada no dia 22/3/2011.

18 Anotações de caderno de campo de observação realizada no dia 22/3/2011.

${ }^{19}$ Este convidado também já esteve em sala de aula, mas no momento em que a pesquisa foi realizada dia encontra-se afastado das salas de aula por ocupar cargo administrativo.

20 Anotações de caderno de campo de observação realizada em 22/3/2011.

${ }^{21}$ Essa atividade foi incluída em virtude de um imprevisto que impossibilitou a realização de outra atividade programada.

${ }^{22}$ Entrevista realizada em 9/6/2011.

${ }^{23}$ Entrevista realizada em 9/6/2011.

${ }^{24}$ Entrevista realizada em 19/4/2011.

Recebido: 02/07/2012

Aprovado: 04/12/2012

Contato:

Universidade Federal de Minas Gerais

Faculdade de Educação

Av. Presidente Antônio Carlos, 6627

CEP $31270-901$

Belo Horizonte, MG

Brasil 